\title{
A NOÇÃO DE ERRO PELO VIÉS DA FALHA: DISCUSSÕES SOBRE A PRÁTICA DA ESCRITA EM LÍNGUA ESPANHOLA
}

\author{
Karla Janaína Alexandre da Silva ${ }^{1}$ \\ Fabiele Stockmans De Nardi ${ }^{2}$
}

\begin{abstract}
Resumo: Partindo das noções teóricas de língua e de sujeito tais como as compreende a AD (PÊCHEUX, 2009), o presente trabalho discorre sobre questões relacionadas à escrita em aulas de espanhol como língua estrangeira (E/LE). Através do tratamento que a escrita recebe nos livros didáticos, discutimos os modos de abordar o erro e as práticas decorrentes de sua identificação na construção de uma relação entre o sujeito-aprendiz e a língua estrangeira. Pretendemos avançar na discussão teórica sobre a falha (AD) e contribuir para ela seja vista como um importante elemento a ser observado pelo professor que, sem desconsiderar a necessidade de trabalhar questões de ordem linguística emergentes dessa prática, possa compreendê-la como um modo de o sujeito emergir no texto.
\end{abstract}

Palavras-chaves: Escrita. Língua Espanhola. Falha.

Abstract: Based on the theoretical notions of language and subject as understood by speech analysis (PÊCHEUX, 2009), the present work deals with questions related to writing in Spanish as a foreign language (S /FL) during classes. Through the treatment that writing receives in textbooks, we discuss ways of approaching mistakes and practices arising from its identification in the construction of a relation between the subjectapprentice and the foreign language. We intend to go forward the theoretical discussion about failure and contribute to it as an important element to be observed by the teacher who, without disregarding the need to work on linguistic issues emerging from this practice, can understand it as a way for the subject to emerge in the text.

Keywords: Writing. Spanish language. Failure.

\section{Introdução}

Atividades que envolvem a escrita são recorrentes nos livros didáticos de espanhol que circulam na escola pública brasileira. Entretanto, o escrever proposto por esses materiais não necessariamente configura-se como uma prática discursiva. É comum encontrar nos livros exercícios em que a escrita objetiva apenas uma retomada de conteúdos gramaticais /lexicais, a reprodução de estruturas como um mero exercício de fixação/memorização, sem que haja espaço para que o sujeito-aprendiz possa posicionar-se discursivamente através da outra língua (DE NARDI, 2007; SILVA, 2014).

O fato é que ao sugerir a escrita como retomada e/ou reprodução de conteúdos linguísticos, sem uma maior atenção aos aspectos discursivos relacionados a esse processo, contribuímos para o engessamento, a instrumentalização da prática e, consequentemente, para a instrumentalização das línguas estrangeiras, em nosso caso, da língua espanhola no Brasil que, tomada como veicular, passa a ser dita e pensada a partir de um discurso do 'mercado', do utilitarismo, da apropriação urgente e da competência, impedindo que ela seja trabalhada em seu caráter formativo.

Nesse sentido, alinhamo-nos a reflexões como as de Celada (2008), que ao falar sobre a relação específica entre língua espanhola e o português brasileiro, propõe pensar, na contramão dessa instrumentalização, em que as línguas fazem trabalhar processos de subjetivação. Diz a autora:

Neste sentido, retomando o que dissemos no início deste texto, consideramos que a instrumentalização a que são submetidas às línguas estrangeiras no mundo

\footnotetext{
${ }^{1}$ Mestre em Linguística pela Universidade Federal de Pernambuco (UFPE). Professora efetiva no Instituto Federal de Alagoas (IFAL). Endereço eletrônico: silvakarlajanaina@gmail.com.

${ }^{2}$ Doutora em Linguística pela Universidade Federal do Rio Grande do Sul (UFRGS). Professora efetiva na Universidade Federal de Pernambuco (UFPE). Endereço eletrônico:fabielestockmans@gmail.com.
} 
contemporâneo não favoreceria esses processos, pois esta, de nossa perspectiva, pressupõe um sujeito pragmático e a necessidade de atender às suas urgências, satisfazendo a "imagem de dominar a língua", muito mais do que solicitando dele que se filie a um saber ou a uma memória. A estrutura da língua é submetida aí a instâncias do imperativo da comunicação e o risco é de que possa ser sacrificado o que o espanhol (como qualquer outro simbólico) quer ou solicita do campo de uma subjetividade [...]. (CELADA, 2008, p. 161)

Tais procedimentos tendem a reduzir a língua à sua estrutura e a aprendizagem dessa língua à repetição de tais estruturas, previamente estabelecidas. Quando olhamos para as práticas de escrita, portanto, observamos que essa redução afeta a própria compreensão do que seja escrever, ou constituir-se como escritor-escrevente, determinando também uma forma de compreensão do que é o certo e o errado em termos de língua e escrita: aquilo que escapa ao modelo proposto pela escola acaba sendo considerado como erro e limita as possibilidades de o sujeito realizar o movimento de autoria.

Pensando sobre essas questões e com base nas noções teóricas de língua e de sujeito apresentadas pela Análise do Discurso de linha pecheuxtiana (AD), propomos discutir a noção de erro pelo viés da falha.

A noção de falha remete ao processo lacunar pelo qual se realiza a constituição do sujeito e da língua. No entremeio entre os elementos da interioridade (sistema linguístico) e da exterioridade (história e os sujeitos), a língua configura-se "como um espaço de regras atravessado por falhas" (GADET et al, 2011). A falha constitutiva da língua é o que nos possibilita pensar o lugar da contradição, da falta, do equívoco, sobre a sua materialidade, resultando no não fechamento dos sentidos.

Por atravessamentos da ordem do ideológico e do inconsciente o sujeito se constitui enquanto "ser-em-falta" (LEANDRO FERREIRA, 2005) e se inscreve no campo discursivo da língua. A falta constitutiva é o elemento que impossibilita o sujeito de ter o controle da língua e não falhar nas práticas que realiza através dela.

A falha é, nessa perspectiva, inerente à relação do sujeito com a língua, porque algo sempre falha nesse processo de o sujeito tomar a língua para dizer (se). Desse modo, pensar numa língua "sob controle", sob o controle do sujeito, é uma ilusão necessária para aquele que se faz sujeito na língua. Trata-se, portanto, de uma ilusão de controle, já que é impossível para o sujeito-aprendiz controlar a língua estrangeira e evitar a falha nas práticas que realiza através dela.

Essas considerações nos permitem, por um lado, reconfigurar a compreensão de erro e, por outro, pensar que esse "erro" é inevitável, demandando do professor uma postura que vá para além da correção e o permita um (re) pensar constante sobre o modo como ele propõe as atividades escolares.

Em relação à escrita em espanhol como língua estrangeira (E/LE), pensamos que o falhar do sujeito-aluno na LE poderá ser interpretado pelo professor sob três perspectivas diferentes: como um reflexo dos limites desse sujeito na língua estrangeira (o que remete à sua condição de ser-em-falta); como mostra da resistência do sujeito-aprendiz a essa nova discursividade, ou como um indício da sua maneira particular de inscrever-se nesse novo espaço de dizer.

Consideramos essa última alternativa como essencial às práticas de escrita em E/LE, pois que a falha poderá ser um elemento revelador do movimento de autoria realizado pelo sujeito-aluno ao escrever na língua estrangeira.

Sendo assim, gostaríamos de evidenciar duas questões nesse trabalho: a primeira diz respeito à atenção necessária com o modo como são propostas as atividades de escrita no LD; a segunda, em como as reflexões teóricas sobre a falha, a partir do campo da AD, nos permitem ressignificar o trabalho com o "erro". 
Seguiremos apresentando dois exemplos de atividades extraídas de livros didáticos de espanhol para brasileiros que nos permitirão dar continuidade a essa discussão.

\section{A escrita no livro didático de espanhol}

As atividades de escrita expostas aqui correspondem a exercícios propostos em duas das coleções didáticas selecionadas pelo Programa Nacional do Livro Didático (PNLD), para uso e consumo na escola pública brasileira durante o triênio 2012-2015 $5^{3}$. Descreveremos os materiais como LD1 e LD2, respectivamente.

Em relação ao processo de ensino-aprendizagem da língua espanhola, ambos os materiais afirmam considerar o contexto sociocultural e os sujeitos que nele estão inseridos como elementos essenciais à percepção dos sentidos que atravessam essa língua estrangeira e influenciam no modo como ela se organiza. Tal posicionamento demonstra o desejo dos livros de romper com a perspectiva que tradicionalmente é adotada na escola, baseada no estudo prescritivo, normativo das línguas.

Entretanto, a disposição, os objetivos e o desenvolvimento das atividades revelam demasiada preocupação, por parte dos materiais, em sistematizar conteúdos linguísticos estudados anteriormente. Vejamos os exemplos a seguir.

Em LD1, a atividade de escrita analisada encontra-se em uma seção intitulada ¡Evalúate! e o seu objetivo didático é avaliar os conteúdos linguísticos trabalhados durante o capítulo. A unidade em questão, ¿Qué te gusta?, discute preferências e hábitos alimentares. $\mathrm{O}$ exercício parte de uma charge do cartunista chileno Alberto Montt ${ }^{4}$.

Fig.1: LD1, seção Evalúate

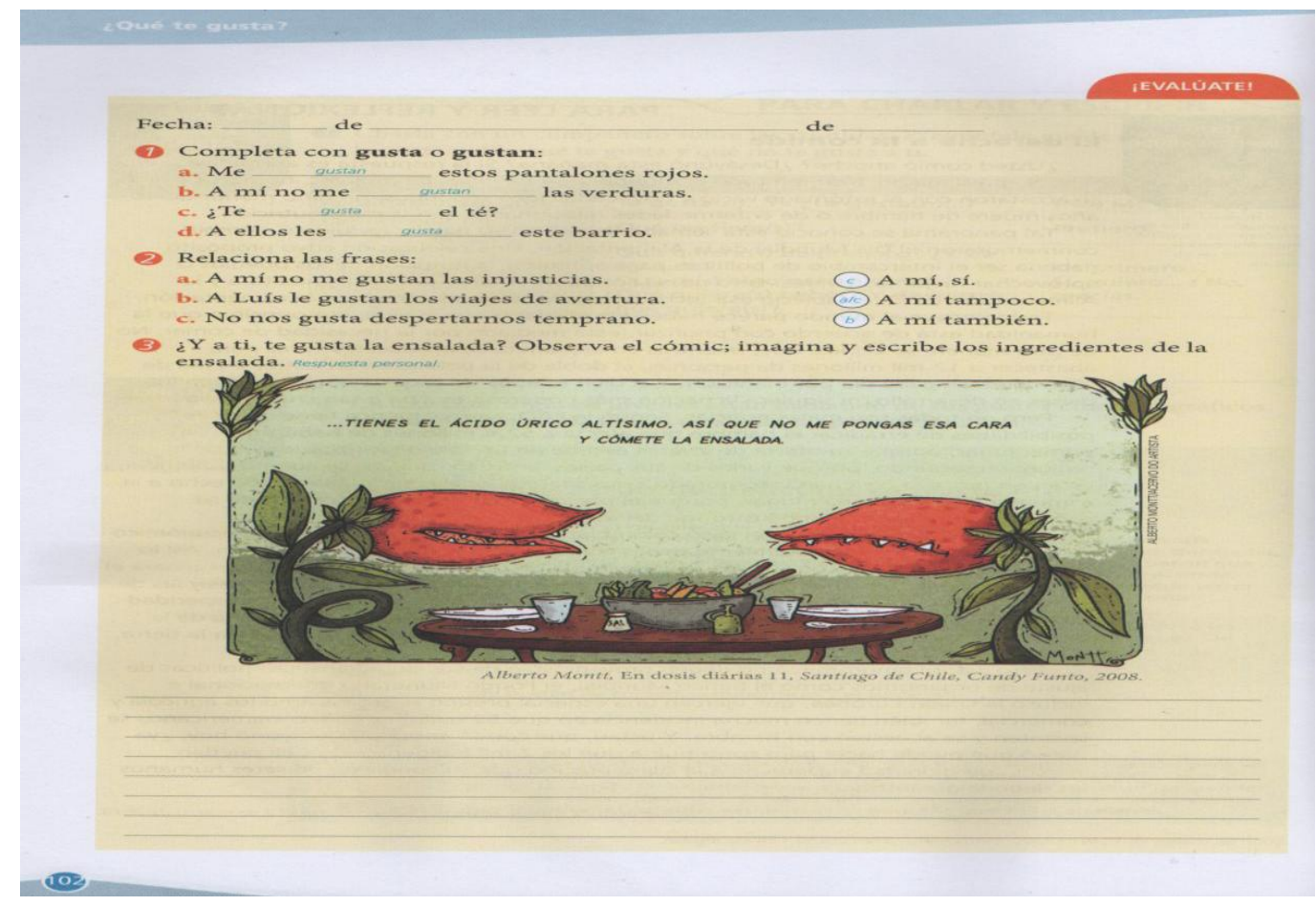

(MARTIN, 2011, p.102, v.1)

\footnotetext{
${ }^{3} \mathrm{Na}$ ocasião, desenvolvíamos uma pesquisa (SILVA, 2014) sobre o tratamento dado à escrita no livro didático de espanhol e essas atividades fizeram parte do nosso corpus de análise.

${ }^{4}$ Sobre Albert Montt ver http:www.dosisdiarias.com, acesso em 20/11/2017
} 
Na charge, duas plantas carnívoras estão sentadas à mesa, diante de um prato de saladas. Uma diz para a outra: “... tienes el ácido úrico altísimo. Así que no me pongas esa cara y cómete la ensalada" ". Como produção escrita, o material solicita ao aluno que, a partir da observação da charge, escreva quais os alimentos que ele acha que compõem a salada que aparece ilustrada no texto.

Pelo desenvolvimento da atividade, LD1 apenas sugere a retomada de um vocabulario relacionado ao tema da unidade didática (alimentos), mas não propõe nenhuma reflexão sobre o contexto de produção discursiva do gênero (o que é uma charge, as finalidades do gênero, o que diferencia esse gênero de outros gêneros, quem é Alberto Montt, etc.) e de compreensão dos sentidos que a atravessam (o que faz desse texto uma charge? qual o humor que está presente na mesma?). O papel da charge na atividade é meramente ilustrativo, não tem uma função social.

No Manual do professor, LD1 afirma que a seção em que se encontra essa atividade (¡Evalúate!), tem por objetivo "apresentar uma proposta de avaliação dos conteúdos trabalhados através de questões discursivas", mas a proposta não se concretiza, já que o exercício consiste em listar os possíveis ingredientes da salada ilustrada na charge.

Pensamos que uma abordagem desse texto através da sua leitura, de modo que o sujeito-aluno compreendesse, em linhas gerais, os sentidos que a atravessam e que a tornam cômica (plantas carnívoras comendo saladas, por conta do ácido úrico!), seguida de uma boa discussão sobre a necessidade do cuidado com a alimentação para assegurar a saúde (menos carne vermelha para evitar a produção excessiva de ácido úrico pelo organismo), resultaria em um interessante trabalho de produção textual.

Entretanto, o que vemos em LD1 é uma atividade de escrita que não possibilita ao sujeito-aluno posicionar-se com base na produção de sentidos, mas que se configura como uma mera sistematização dos conteúdos linguísticos que foram estudados no capítulo.

Exemplo semelhante é observado em LD2. A atividade consiste na produção de um texto no gênero discursivo horóscopo, a partir de um modelo. Desde o enunciado da questão, o material já sinaliza para os alunos as características do gênero (sem deixar que eles construam, por inferência, essa informação). Há apenas um único questionamento sobre o texto modelo (¿Qué habilidad de géminis se destaca en el texto?). Contudo a resposta pode ser facilmente localizada nas duas primeiras linhas do texto. Em seguida, LD2 propõe que, em grupos, sejam produzidos horóscopos, conforme as instruções apresentadas.

LD2 também pontua aspectos linguísticos e gramaticais relacionados à estrutura composicional do gênero horóscopo e em seu Guía del Profesor sugere ao docente levar exemplos no mesmo gênero para a sala de aula, no intuito de explorar as características mencionadas.

O fato curioso é que a atividade está inserida na unidade intitulada Hagamos un trato, cujo tema abordado é a prevenção de doenças sexualmente transmissíveis e questões de gênero, ou seja, o exercício não apresenta uma ligação direta com o tema que é estudado nesse capítulo.

A proposta de escrita de LD2 somente se justifica pelo conteúdo gramatical que é abordado durante a unidade: usos de verbos no tempo Condicional e de pronomes e adjetivos indefinidos (em português corresponde ao futuro do pretérito e aos pronomes indefinidos, respectivamente).

Ao observarmos com atenção os quadros que apontam para o texto que ilustra a atividade, veremos que aparecem as indicações de utilização desse conteúdo gramatical.

\footnotetext{
${ }^{5}$ Uma tradução possível: “... estás com o ácido úrico altíssimo. Então, não faz essa cara e come a salada”.
} 


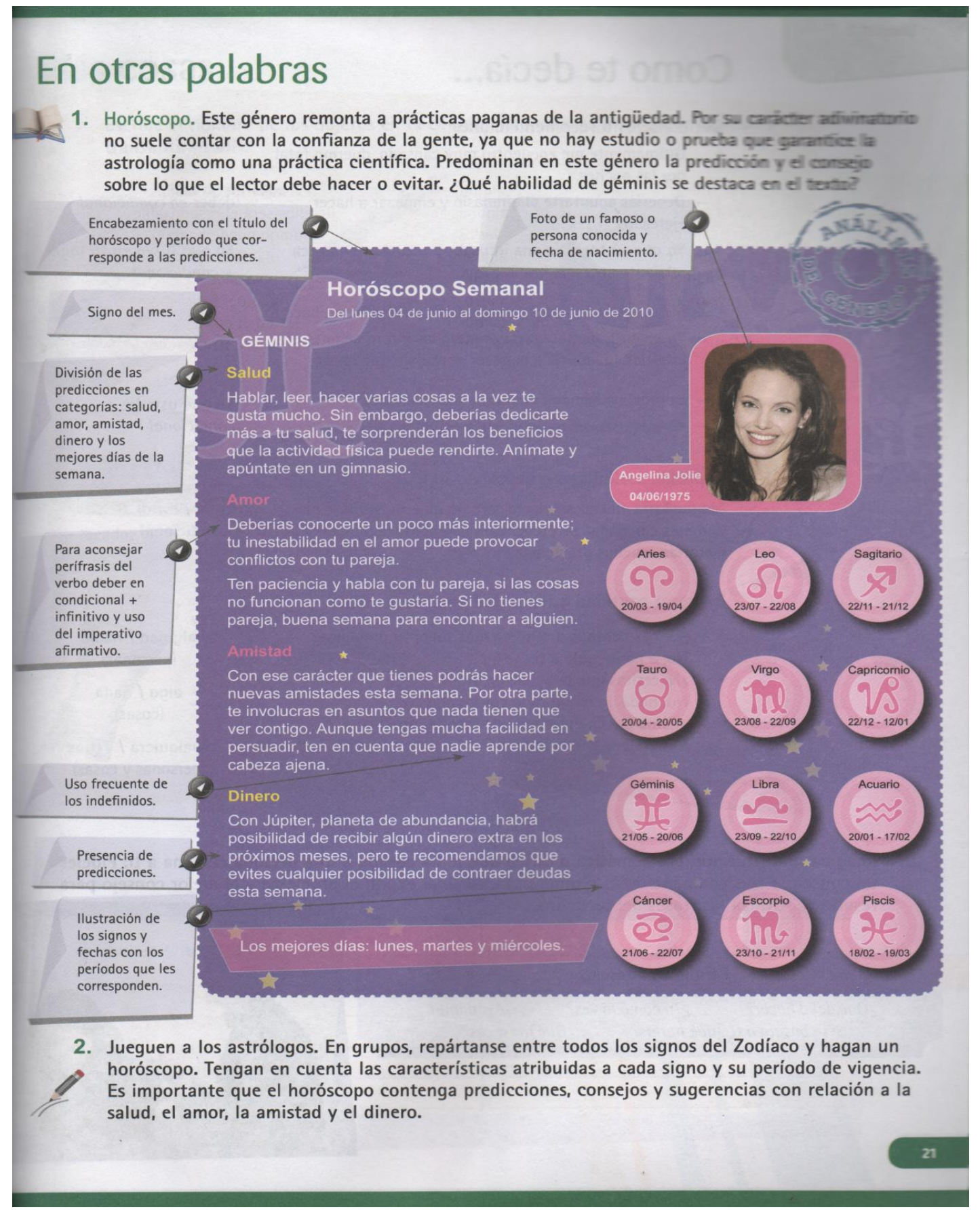

(OSMAN et al, 2010, p.21, v.3)

Dessa forma, assim como em LD1, a atividade de escrita presente em LD2 tem como objetivo apenas sistematizar, retomar os conteúdos gramaticais e lexicais estudados, sem uma maior preocupação em possibilitar ao aluno um trabalho sobre os sentidos, de modo a levá-lo a posicionar-se discursivamente durante o processo de escrita.

Destacamos ainda outros dois aspectos, em relação aos exercícios de escrita propostos por esses materiais didáticos: o primeiro diz respeito à disposição dessas atividades nos livros. Em ambos os livros, os exercícios de escrita sempre aparecem entre as últimas seções dos capítulos de cada volume, obedecendo a uma mesma ordem: introdução da 
temática discutida na unidade, exploração de vocabulário e de estruturas gramaticais relacionadas ao capítulo, seguido de atividades de leitura, de sistematização gramatical e, por fim, atividades de produção escrita.

A segunda questão refere-se aos objetivos das atividades. No manual do professor de LD1 a produção escrita é descrita como "uma ampliação da atividade oral (MARTIN, 2011, p.06). Já em LD2, a escrita é vista como uma possibilidade de "sistematizar a habilidade do aluno em analisar a configuração de diferentes gêneros [...] para uma posterior reprodução" (OSMAN et al, 2010, p.04).

O modo como esses materiais didáticos propõem e desenvolvem as atividades de escrita em espanhol nos recorda as palavras de Camargnani (1999, p.129), quando afirma que a escrita no livro didático de língua estrangeira é sempre vista como uma prática secundária e que "camufla o desejo de fixação da gramática da língua, do vocabulário e de outros aspectos formais nem sempre assumidos como objetivos das atividades".

Essa tentativa de levar o aluno a fixar a língua através da escrita também revela uma compreensão da relação do sujeito-aprendiz com a língua estrangeira como um processo não subjetivo, que se configura pelo desejo de dar ao sujeito o controle da língua. Nesse sentido, as práticas de escrita dos referidos materiais corroboram ao processo de instrumentalização da língua espanhola (CELADA, 2008) e, consequentemente, a uma não discussão (na escola) sobre o que, efetivamente, representa escrever.

Ora, ao tentar oferecer ao sujeito-aluno o controle da língua estrangeira, contribuímos para a criação de um modelo de escrita que se baseia na reprodução, na repetição de algo que está dito (pelos livros, pelo professor) e não na construção de um dizer por parte do sujeito-aluno. É o apagamento do sujeito no texto.

Além disso, ao limitar as possibilidades de dizer do sujeito-aprendiz (no texto), também favorecemos a um entendimento de que, aquilo que escapa ao que foi préestabelecido (pelo livro, pelo professor), deve ser considerado como erro. Entretanto, pelo próprio processo subjetivo de constituição da língua e do sujeito e da relação entre eles, não há como o sujeito ter controle sobre as práticas que realiza através da língua. Ou seja, não há escrita livre de falha.

Com essas colocações, não estamos pregando um trabalho com a escrita que descarte do processo de ensino-aprendizagem do espanhol os aspectos formais/ normativos dessa língua estrangeira, mas ressaltar que é preciso permitir a mobilização do sujeito-aprendiz ${ }^{6}$ durante o processo de produção textual.

Portanto, é preciso que lancemos um olhar mais cauteloso ao processo de produção escrita. Um olhar que parta do entendimento de que escrever na língua estrangeira vai muito mais além que o jogo nas regras da língua (PÊCHEUX, 1998), ou seja, escrever não corresponde apenas a uma retomada, a uma reprodução daquilo que está estabilizado na estrutura da língua espanhola. Mas, compreender que a escrita demanda o jogo sobre as $\operatorname{regras}^{7}$, isto é, a inserção do sujeito-aprendiz nessa nova discursividade, movimento que lhe permite ultrapassar o campo da reprodução e dizer-se na outra língua.

E uma vez que a língua não está a serviço do sujeito, mas o sujeito que se submete a ordem discursiva da mesma é preciso lembrar que há limites atravessando a relação do sujeito-aprendiz com a língua estrangeira.

Limites que o impossibilitam de tudo poder dizer, ou significar. Limites que resultam na falha que se mostra através das práticas na língua. Por outro lado, se a falha é vista como

\footnotetext{
${ }^{6}$ Quando falamos em mobilização do sujeito no texto, referimo-nos ao processo discursivo de "textualização". O que, conforme Gallo (2008, p.44) deve ser compreendido como "prática de fixação, de escrituração de um fragmento", é o trabalho do sujeito sobre os sentidos e o modo como esse movimento discursivo se materializa pela língua estrangeira através do texto.

${ }^{7}$ Ver Pêcheux (1998).
} 
inerente a relação do sujeito-aprendiz com a língua espanhola, poderemos reconfigurar o modo como a compreendemos e como interpretamos a noção de erro. Nas práticas de escrita em E/LE, a falha do sujeito-aprendiz poderá sinalizar o movimento de autoria. Passemos a essas questões.

\section{$3(\mathrm{Re})$ pensando a noção de erro pelo viés da falha}

Embora a noção de falha funcione como uma marca dos limites do sujeito na língua é possível tomá-la por um outro viés. Referimo-nos à compreensão da noção como um indício da maneira particular de cada sujeito constituir-se discursivamente. Pêcheux, em um dos seus anexos de "Semântica e Discurso", nos ajuda a discutir a questão. Dentre as suas colocações, destacamos a seguinte:

Apreender até o seu limite máximo a interpelação ideológica como ritual supõe reconhecer que não há ritual sem falhas; enfraquecimento e brechas, "uma palavra por outra" é a definição da metáfora, mas é também o ponto que o ritual se estilhaça no lapso [...] (PÊCHEUX, 2009, p.277).

Ao colocar o assujeitamento como um ritual que não se realiza sem falhas, Pêcheux (2009) nos induz a pensar a noção de falha, não apenas como uma marca da inscrição do sujeito na língua, mas, principalmente, sobre o que ela pode nos dizer a respeito desse sujeito e sobre as particularidades da realização desse processo. Se há falha no ritual (no assujeitamento) é porque ele não se concretiza da mesma forma para todos os sujeitos, daí refletirmos sobre as minúcias desse mecanismo para o um (o sujeito).

Nesse sentido, a noção de falha proposta pela AD possibilita-nos tramar algumas considerações sobre o processo de subjetivação do sujeito-aprendiz na língua espanhola e como isso se reflete nas práticas de escrita que ele realiza nessa língua estrangeira. Acreditamos que a falha do sujeito-aprendiz na LE, pode ser vista por três direções diferentes: a primeira, como um movimento de resistência do sujeito-aluno ao assujeitamento nesse novo espaço de dizer e que tem origem na sua não identificação com a língua estrangeira.

Por sua vez, a não identificação do sujeito-aprendiz com a língua espanhola poderia ser explicada pelo que afirma De Nardi (2009, p.183), de que a aprendizagem da língua estrangeira remete a algo "que é estranho", que "perturba" e "incomoda" o sujeito-aluno, ou como afirma Coracini (2003, p.149), a não identificação como o "medo do novo, do deslocamento, das mudanças" que a nova aprendizagem representa. E uma das maneiras dessa resistência do sujeito-aprendiz vir à tona é pela presença bem marcada da língua materna na sua escrita em espanhol.

A segunda possibilidade de compreensão da falha do sujeito-aluno, nas práticas de escrita em E/LE, seria tomá-la como parte do processo de inscrição nessa língua estrangeira, isto é, a falha que é provocada pela sua condição "de ser-em-falta" (LEANDRO FERREIRA, 2005) e lhe impossibilita tudo poder dizer ou significar nessa outra língua.

Por esse viés, as marcas da língua materna sobre a escrita em espanhol, as dificuldades de emprego de elementos gramaticais e lexicais, ou até mesmo, a impossibilidade de produzir texto na outra língua, todos esses exemplos funcionariam como um reflexo dessa marcação do sujeito-aluno na LE, enquanto sujeito que se constitui na falta e que não tem controle sobre as práticas que realiza através da língua (seja ela materna, ou estrangeira).

O terceiro movimento que acreditamos ser possível pontuar, em relação à falha do sujeito-aprendiz na escrita em espanhol, corresponderia à sua tentativa de marcar-se como um na outra língua. Em outras palavras, pensamos que a falha do sujeito-aprendiz na língua

\footnotetext{
${ }^{8}$ Em "Só há causa daquilo que falha ou o inverno político francês: início de uma retificação" (PÊCHEUX, 2009).
} 
espanhola pode representar o desejo desse sujeito de mostrar-se em seu texto, pelo efeito de autoria.

Maia (2006), ao falar sobre a subjetivação presente no processo de escrita, coloca que os lapsos do sujeito nessa prática, tais como "repetição, esquecimento de palavras, distorção de nomes, supostos erros tipográficos, ortográficos" podem significar "motivações do inconsciente como meio de expressão de um desejo proibido".

Nesse sentido, a autora propõe considerar a ruptura com o que na língua está estabilizado, como "uma mensagem original e particular do sujeito" (MAIA, 2006, p.35). Por esse viés, a falha do sujeito-aluno nas práticas de escrita em espanhol seria considerada como uma tentativa desse sujeito de evidenciar o desejo de completude que o atravessa, isto é, o desejo de ser um, o desejo que é revelado no texto através da ruptura com o que na língua está estabilizado.

Desse modo, a interferência da língua materna sobre a escrita na língua espanhola, os possíveis "erros" no emprego de normas linguísticas, a insistência no uso de uma determinada palavra, a criação de novas palavras, funcionariam como indícios do posicionamento discursivo do sujeito-aprendiz no processo de textualização, indícios do efeito de autoria.

Pensamos que todos esses exemplos de falha, pelos quais o sujeito pode vir a mostrar-se dentro processo de subjetivação na outra língua, mereciam ser tratados com um pouco mais de atenção pela escola, principalmente, ao serem pontuados para o sujeito-aluno.

Se o professor consegue compreender a falha do sujeito-aluno na língua estrangeira como uma marca da sua inscrição nesse outro lugar, ele tem uma oportunidade de repensar esse processo, ou seja, de não tomar a falha como erro, como algo que precisa ser combatido, mas como fundamental para a visibilidade do aprendiz dentro do processo de ensinoaprendizagem. O que, nas práticas de escrita, funcionaria como uma possibilidade de se enxergar o movimento de autoria que o sujeito-aluno realiza.

Desse modo, a partir desse deslocamento (da falha como marca da inscrição do sujeito na língua e não como erro), temos a oportunidade de levar o sujeito-aluno a refletir sobre as especificidades dessa língua outra que, enquanto materialidade, apresenta suas exigências e solicita aos sujeitos, também, que se assujeitem à sua ordem, aos sentidos que se desencadeiam em seu funcionamento. Então, jogando com o que o aluno produz, o professor pode encontrar na falha um espaço para levá-lo a compreender o que é o próprio da língua estrangeira e que é preciso respeitar.

\section{Considerações finais}

Apesar do desejo de romper com um modelo de estudo prescritivo, normativo do espanhol, comumente adotado pelas escolas brasileiras, os livros didáticos aqui analisados acabam por repetir esse modelo.

Ao sugerir a escrita como uma mera retomada e/ou reprodução de conteúdos linguísticos, sem atentar para os aspectos discursivos relacionados a esse processo, os materiais contribuem para o engessamento, a instrumentalização dessa prática e, consequentemente, para a instrumentalização da língua espanhola, impedindo que ela seja trabalhada em seu caráter formativo.

A redução da língua estrangeira ao estudo de seus aspectos formais e/ou normativos induz a uma equivocada compreensão do que vem a ser relação do sujeito-aprendiz com a língua espanhola, dando a ideia de que o mesmo poderá controlar a língua. Essa redução também afeta o modo como se compreende o processo de escrita e o lugar do sujeito-aprendiz dentro desse processo: o que foge ao modelo proposto pela escola passa a ser considerado como erro. Nas práticas de escrita, a impossibilidade de mover-se para além do que é posto como certo, limita as possibilidades de o sujeito realizar o movimento de autoria. 
Entretanto, se tomarmos à relação entre língua e sujeito como um processo subjetivo que se configura pelo viés da incompletude, incompletude da língua, por ser um espaço de regras atravessado por falhas, e incompletude do sujeito, devido à sua condição de ser-emfalta, veremos que não há como desconsiderar a possibilidade de falha dentro desse processo.

Sendo a falha inerente à relação do sujeito com a língua, ela se constitui como um importante elemento para que possamos (re) pensar a noção de erro, tomando-o para além do jogo de oposição certo/errado, refletindo sobre o que ele representa dentro do processo de ensino-aprendizagem do espanhol como língua estrangeira.

Por outro lado, se a falha é marca da inscrição do sujeito na língua, ela também pode ser entendida como indício da maneira particular de cada sujeito constituir-se discursivamente. Na escrita em E/LE, o falhar do sujeito-aluno poderá ser interpretado como um reflexo dos limites desse sujeito na língua estrangeira (o que remete à sua condição de serem-falta), como mostra da resistência do sujeito-aprendiz a essa nova discursividade, ou simbolizar a sua maneira particular de inscrever-se nesse novo espaço de dizer. Diferentes possibilidades de representação que exigem diferentes posturas do professor.

Portanto, é preciso que estejamos mais atentos ao modo como avaliamos o erro, ao propor atividades de escrita na sala de aula. Que nos mantenhamos críticos em relação ao uso do livro didático.

Nesse sentido, (re) pensar a falha do sujeito-aluno (ao escrever em espanhol) representa um passo importante em direção à construção de um espaço escolar que contribui mais efetivamente ao entendimento da escrita como um processo discursivo, cujo resultado (o texto) sinaliza para o professor de E/LE o caminho percorrido pelo aprendiz na tentativa de fazer-se autor na outra língua.

\section{Referências}

CARMAGNANI, A. M. G. A concepção de professor e aluno no Livro Didático e o Ensino de Redação em LM e LE. In: CORACINI, M. J. (Org.) Interpretação, Autoria e Legitimação do Livro Didático. Campinas: Pontes, 1999, p. 127-135.

CORACINI, M. J. R. F. Língua estrangeira e língua materna: uma questão de identidade In: CORACINI, M. J. R. R (Org.) Identidade e Discurso. Campinas: UNICAMP; Chapecó: Argos, 2003, p. 139-159.

CELADA, M. T. O que quer, o que pode uma língua? Língua estrangeira, memória discursiva, subjetividade. In: Letras. Revista do Programa de Pós-graduação da Universidade de Santa Maria, V. 18 / n. 2, julho-dezembro de 2008.

DE NARDI, F. S. Um olhar discursivo sobre língua, cultura e identidade: reflexões sobre o livro didático para o ensino do espanhol como língua estrangeira. Porto Alegre, 2007. Tese (Doutorado em Teorias do Texto de do Discurso) - Instituto de Letras, Universidade Federal do Rio Grande do Sul.

Entre a rejeição e o acolhimento na língua do outro In: Revista Desenredo. Passo Fundo: Revista do Programa de Pós-graduação da Universidade de Passo Fundo, V. 5, n.2, p.182-193, julho-dezembro de 2009.

GADET, F; HAROCHE, C; HENRY, P; PÊCHEUX, M. Nota sobre a questão da linguagem e do simbólico em psicologia (1982) In: ORLANDI, E. Análise do discurso: Michel Pêcheux. Textos selecionados. Campinas: Pontes, 2011, p.55-71.

GALLO, S. Como o texto se produz: uma perspectiva discursiva. Blumenau: Nova Letra, 2008. 
LEANDRO FERREIRA, M. C. Linguagem, Ideologia e Psicanálise In: Estudos da Língua (gem). Michel Pêcheux e a Análise do Discurso. Vitória da Conquista: [...] v.1, junho/2005, p. 9-15.

MAIA, M. C. G. O lapso da escrita como refúgio do sujeito. In: MARIANI, B (Org.) A escrita e os escritos. São Carlos: Editora Claraluz, 2006, p.31-44.

MARTÍN, I. Síntesis: curso de lengua española. Ensino Médio. São Paulo: Editora Ática, 2011. Volumes I.

OSMAN, S. et al. Enlaces: español para jóvenes brasileños. São Paulo: Macmillan do Brasil, 2010. Volumes III.

PÊCHEUX, M. Sur la (dé-)construction des theories linguistiques (1982), DRLAV, $\mathrm{n}^{\circ} .27$. Tradução brasileira: Sobre a (des) construção das teorias linguísticas. Cadernos de Tradução do Instituto de Letras da UFRGS. $2^{\text {a }}$ ed. Porto Alegre, n. 04, out. 1998, p. 35-55.

Editora UNICAMP, 2009.

Semântica e Discurso: uma crítica à afirmação do óbvio (1975). Campinas:

SILVA, K. J. A. Os (des) caminhos da escrita na aula de escrita de língua estrangeira: Língua, sujeito e autoria no livro didático de E/LE. Recife, 2014. Dissertação (Mestrado em Linguística)- Pós-graduação em Letras, Universidade Federal de Pernambuco. 